\title{
APPLICATION OF MANGANESE OXIDE THIN-FILMS OBTAINED BY ALD FOR LI-ION BATTERIES ANODE
}

\author{
Ilya EZHOV, Paul VISHNIAKOV, Ilya MITROFANOV, Yury KOSHTYAL, Denis NAZAROV, \\ Aleksander RUMYANTSEV, Anatoliy POPOVICH, Maxim MAXIMOV* \\ Peter the Great Saint-Petersburg Polytechnic University, Saint-Petersburg, Russia, “maximspbstu@mail.ru
}

https://doi.org/10.37904/nanocon.2020.3715

\begin{abstract}
Thin-film solid-state lithium-ion batteries can provide autonomous operation of miniature devices (biosensors, smartwatches, medical devices, etc.). In this work, we investigated the processes of obtaining thin films of manganese oxide by atomic layer deposition (ALD), and their electrochemical activity as an anode of a lithiumion battery (LIBs). Tris (2,2,6,6-tetramethyl-3,5-heptanedionato) manganese (III) ( $\mathrm{Mn}$ (thd) $)_{3}$ ) was used as an $\mathrm{Mn}$ precursor, and remote oxygen plasma was used as a co-reactant. Each pulse of $\mathrm{Mn}(\mathrm{thd})_{3}$ and remote plasma treatment were separated by $\mathrm{N}_{2}$ purge and evacuation of the reactor. The deposition of manganese oxide films was carried out on silicon (100) and stainless steel (316SS, $16 \mathrm{~mm}$ in diameter) substrates at the temperature of $250-300{ }^{\circ} \mathrm{C}$. The effect of the precursor sublimation temperature, the pulse of manganese precursor, and purge time on the growth rate per cycle was studied. The average growth per cycle calculated from film thickness measurements (spectral ellipsometry) varied from 0.06 to $0.12 \AA /$ cycle. Using X-ray photoelectron spectroscopy (XPS), the compositions of the deposited films were determined. According to XPS results, the formation of $\mathrm{Mn}_{2} \mathrm{O}_{3}$ oxide occurred during deposition. The change in the shape of the curves of cyclic voltammetry as a result of cyclic charge/discharge relative to lithium is discovered. The maximum capacity observed at $0.8 \mathrm{C}$-Rate $(30 \mu \mathrm{A})$ was $110 \mu \mathrm{Ah} \cdot \mu \mathrm{m}^{-1} \cdot \mathrm{cm}^{-2}$ for a steel substrate with a manganese oxide layer.
\end{abstract}

Keywords: Atomic layer deposition, manganese oxide, thin films, solid-state li-ion battery

\section{INTRODUCTION}

Nowadays, most electronics companies try to reduce the size of their product. Due to this fact, the downsizing of power-supply sources is the current problem for them. There is a need for methods that can accurately recreate the structure of the battery and its materials while improving the parameters compared to old ones. The synthesis of thin-film cathode and anode materials by atomic layer deposition (ALD) allows solving this problem. The method is based on self-limiting reactions of a gas-phase reagent with a substrate surface $[1,2]$. Due to its peculiar properties, the process makes it possible to create uniform coatings on substrates of complex shapes such as high-aspect structures [3,4]. Therefore, the energy capacity of the battery can be increased, which has a positive effect on the device's autonomy. Studies [5-7], have shown that ALD coatings the oxides of transition metals such as $\mathrm{Ni}$, Co, have high electrochemical activity. Manganese oxides have similar electrochemical characteristics [8]. Thus, it can appear for high-capacity anode material of a thin-film lithium-ion battery.

Various compounds are used to synthesis thin films of manganese oxides by the ALD. The most common are manganese carbonyl $\mathrm{Mn}_{2}(\mathrm{CO})_{10}$ [9], Bis(ethylcyclopentadienyl)manganese (II) $\mathrm{Mn}(\mathrm{EtCp})_{2}$ [10,11], and

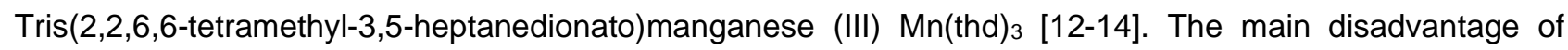
$\mathrm{Mn}_{2}(\mathrm{CO})_{10}$ is the difficulty of controlling the uniform growth of films at elevated temperatures due to the reagent decomposition. In the case of using $\mathrm{Mn}(\mathrm{EtCp})_{2}$, the resulted manganese oxides generally have a stoichiometric 
formula close to $\mathrm{MnO}$. Thus, stronger oxidation conditions are required to obtain manganese oxides with higher oxidation states.

In this work, $\mathrm{Mn}$ (thd) $)_{3}$ was chosen as a precursor due to the stable average growth per cycle rate and uniformity of the films. Another advantage is the possibility of synthesis of manganese oxides in a wide range of oxidation states from +2 to +4 by varying the second reagent [10]. This work describes ALD synthesis and studies (physicochemical and electrochemical) of films obtained by ALD synthesis thin films of manganese oxide using $\mathrm{Mn}(\text { thd })_{3}$ as a reagent, as well as to identify the optimal synthesis parameters.

\section{MATERIALS AND METHODS}

Silicon monocrystal plate (111, 40 мm, ZAO "Svetlana") and stainless-steel plate (316SS, Tob New Energy Technology Co., LTD, $15.8 \mathrm{~mm}$ ) were used as a surface for the thin film deposition. Steel plates were cleaned in Ultrasonic cleaner, acetone, and deionized water for 15 minutes successively.

ALD of the thin film was performed in the «Functional materials» laboratory, SPbPU using Picosun R-150 setup at the reactor temperature of $270^{\circ} \mathrm{C}$ and the reactor pressure of 8-12 $\mathrm{GPa}$. Tris(2,2,6,6-tetramethyl-3,5heptanedionato)manganese(III) (Mn(thd) 3 ) (CAS № 14324-99-3, DalChem) was used as a precursor. Oxygen plasma was used as a co-reactant (Power- $3 \mathrm{~kW}$, pulse - $15 \mathrm{~s}$ ).

Spectroscopic ellipsometry parameters for the $\mathrm{Mn}_{2} \mathrm{O}_{3}$ film was measured by ellipsometer SAG Ellips-1891 (CNT, Novosibirsk, Russia) in wave range from 350 to $1000 \mathrm{~nm}$.

Electrochemical measurements were carried out on coin cells with CR2032 dimensions relative to lithium. MnO samples on the $316 S S$ surface were used as an electrode. Lithium foil, polyolefin porous film 2325 (Celgard, Charlotte, North Carolina, USA), and TC-E918 solution (Tinci, Guangzhou, China) were used as a counter electrode, separator, and electrolyte, respectively. Disc cells were collected in the OMNI-LAB (VAC) glove box under argon atmosphere. Cyclic voltammetry (CV) was performed using the PGSTAT302N+ potentiostat (Autolab, Utrecht, Netherlands) in the range of $0-3.0 \mathrm{~V}$ at a scan velocity of $0.5 \mathrm{mV} / \mathrm{s}$.

X-ray photoelectron spectra (XPS) were detected with "Thermo Fisher Scientific Escalab 250Xi". The surface of samples was etched by Ar ions with an energy of 500-3000 eV before the measurements. Then samples were illuminated by the x-ray emission of $\mathrm{Al} \mathrm{Ka}(1486,7 \mathrm{eV})$ in vacuum $7 \cdot 10^{-8} \mathrm{~Pa}$. Sample charging was automatically compensated. Analysis for each sample was carried out at 2-3 randomly selected points on the surface.

X-ray diffraction (XRD) studies were performed using a Bruker D8 ADVANCE (Cu-Ka, Billerica, MA, USA).

\section{RESULT AND DISCUSSION}

\subsection{Mn-O thin films synthesis}

Different deposition parameters were varied during the experiment to determine their influence on the growth parameters of the films. Experimental parameters and growth results are presented in Table 1.

Deposition parameters consisted of the temperatures of the evaporator $\left(170-190{ }^{\circ} \mathrm{C}\right)$, the temperature of the reagent supply line to the reactor $\left(200-210^{\circ} \mathrm{C}\right)$, and the pulse time of the manganese precursor $(0.5-4 \mathrm{~s})$. The growth rate was studied on films resulting from 500 ALD cycles. Thicker films were grown (over 1700 cycles) to research chemical, phase compositions and determine the electrochemical characteristics. The purge time for all experiments was 3 seconds after the $\mathrm{Mn}(\mathrm{thd})_{3}$ injection. The time of the pulse and purging of oxygen plasma was 15 and 5 seconds, respectively. Experimental parameters and growth conditions are presented in Table 1. 
The study showed that the growth rate doubled from 0.06 to $0.12 \AA /$ cycle, with an increase in the evaporator temperature from 170 to $190^{\circ} \mathrm{C}$. Such a difference is caused by the vapor pressure rise of $\mathrm{Mn}(\mathrm{thd})_{3}$ in the evaporator and, consequently, in the reactor. Furthermore, the uniformity of the coatings improves with an increase of the pulse duration at the minimum investigated temperature of the evaporator $\left(170{ }^{\circ} \mathrm{C}\right)$. Still, the average growth per cycle does not increase significantly. An increase in the precursor's pulse time from 0.5 to $2 \mathrm{~s}$ at $190{ }^{\circ} \mathrm{C}$ leads to a nonlinear increase in the growth rate. The maximum growth per cycle was recorded at a $1 \mathrm{~s}$ pulse with maintaining the uniformity of the coating constant. This time is sufficient to saturate the substrate with reagent vapors. Subsequent increase pulse time may cause a purge effect, which promotes reagent desorption and a decrease in the growth rate per cycle.

Table 1 Influence of synthesis parameters on the growth rate of manganese oxide films

\begin{tabular}{|c|c|c|c|c|}
\hline $\mathbf{T}_{\text {source }} / \mathbf{T}_{\text {line }}$ & $\begin{array}{c}\text { Pulse Mn(thd) })_{3} / \\
\text { Purge }\end{array}$ & Thickness & Growth per cycle & Cycle \\
\hline${ }^{\circ} \mathrm{C}$ & s & $\mathrm{nm}$ & Â/ cycle & $\mathbf{n}$ \\
\hline $170 / 210$ & $1.0 / 3.0$ & $2.0-3.8$ & $0.06 \pm 0.01$ & 500 \\
\hline $170 / 210$ & $4.0 / 3.0$ & 2.9-3.7 & $0.07 \pm 0.01$ & 500 \\
\hline $180 / 200$ & $1.0 / 3.0$ & $3.3-3.8$ & $0.07 \pm 0.01$ & 500 \\
\hline $190 / 200$ & $0.5 / 3.0$ & $3.2-4.6$ & $0.08 \pm 0.01$ & 500 \\
\hline $190 / 200$ & $1.0 / 3.0$ & $5.0-6.3$ & $0.12 \pm 0.01$ & 500 \\
\hline $190 / 200$ & $2.0 / 3.0$ & $3.8-4.9$ & $0.09 \pm 0.01$ & 500 \\
\hline $190 / 200$ & $1.0 / 3.0$ & $12.6-20.7$ & $0.10 \pm 0.01$ & 1700 \\
\hline
\end{tabular}

It should be noted that the reagent is stable up to $240{ }^{\circ} \mathrm{C}$ [15]. Hence, a further increase in the evaporator temperature would lead to unwanted decomposition of the reagent.

Consequently, deposition conditions with the highest growth rate were chosen to grow a thick manganese oxide film (1700 cycles): the deposition temperature is $190^{\circ} \mathrm{C}$, the precursor pulse and purge times are 1 and 3 seconds, respectively. The average growth per cycle for samples obtained at 500 and 1700 cycles is approximately the same and varies in the range of $0.10-0.12 \AA /$ cycle.

\subsection{Mn-O thin films characterization}

To determine the chemical composition, the obtained samples were examined using X-ray photoelectron spectroscopy. Before measurements, the surface was etched with argon ions ( $3 \mathrm{keV}$ ) for 30 seconds to remove surface contamination. It was found that the coating in the analyzed region contains 63.8 at. \% oxygen, 26.8 at. \% manganese and 9.4 at. \% carbon. Thus, the ratio of oxygen to manganese is 1.43 (63.8/26.8), closest to $\mathrm{Mn}_{2} \mathrm{O}_{3}$. The high carbon content in the film is associated with carbon-containing contaminants during etching and incomplete removal of the residues of the precursor ligands. Two peaks are observed on the $\mathrm{C} 1 \mathrm{~s}$ spectrum (Figure 1a), corresponding to $\mathrm{C}-\mathrm{C}, \mathrm{C}-\mathrm{H}$ bonds, and carbonates $\left(\mathrm{CO}_{3}{ }^{2-}\right)$.

On the O1s spectrum (Figure 1b) appear two peaks at $529.8 \mathrm{eV}$ and $531.9 \mathrm{eV}$. The former refers to the compounds of oxygen with manganese in $\mathrm{Mn}_{2} \mathrm{O}_{3}$. The latter corresponds to oxygen in hydroxyl groups and/or carbonate.

The Mn2p spectrum (Figure 1c) contains two peaks with maxima at $641.4 \mathrm{eV}(\mathrm{Mn} 2 \mathrm{p} 3 / 2)$ and $653.1 \mathrm{eV}(\mathrm{Mn}$ $2 \mathrm{p} 1 / 2$ ), which correspond to the compound $\mathrm{Mn}_{2} \mathrm{O}_{3}$. As a result, separation of the Gaussian curves, it was found that the analyzed part of the sample might contain a small proportion of $\mathrm{MnO}_{2}$. 


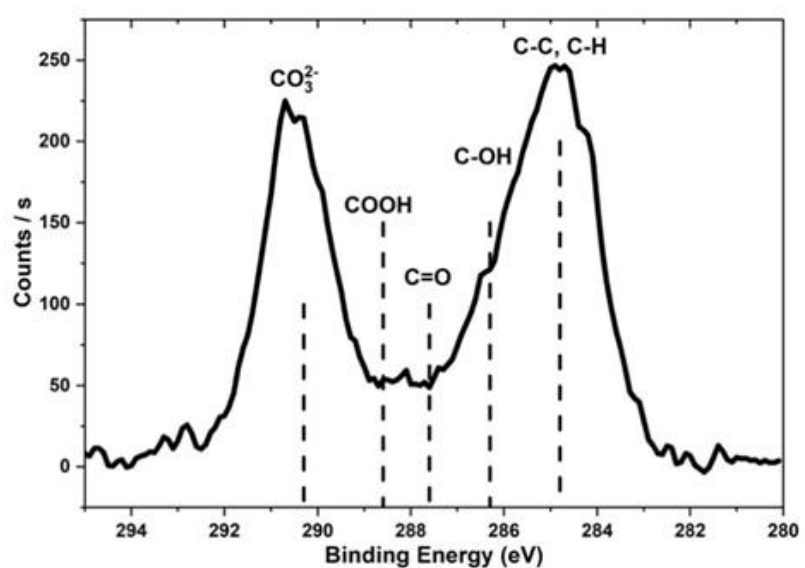

(a)

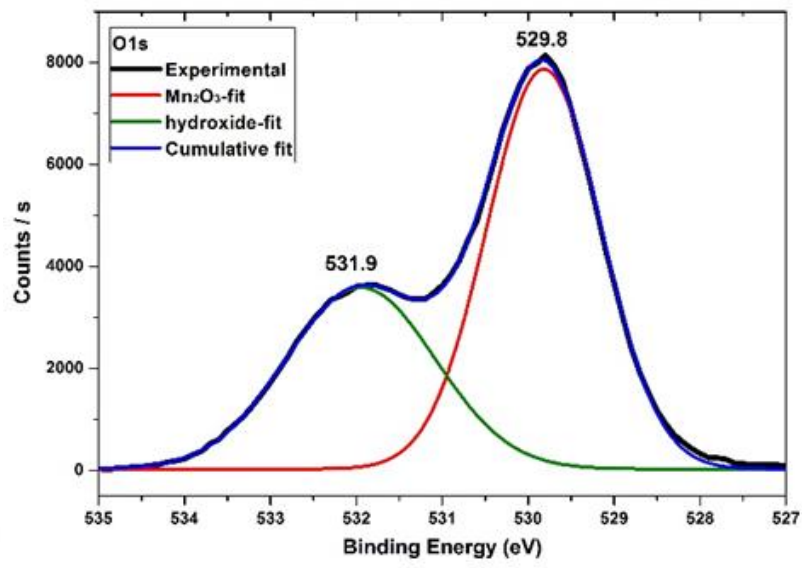

(b)

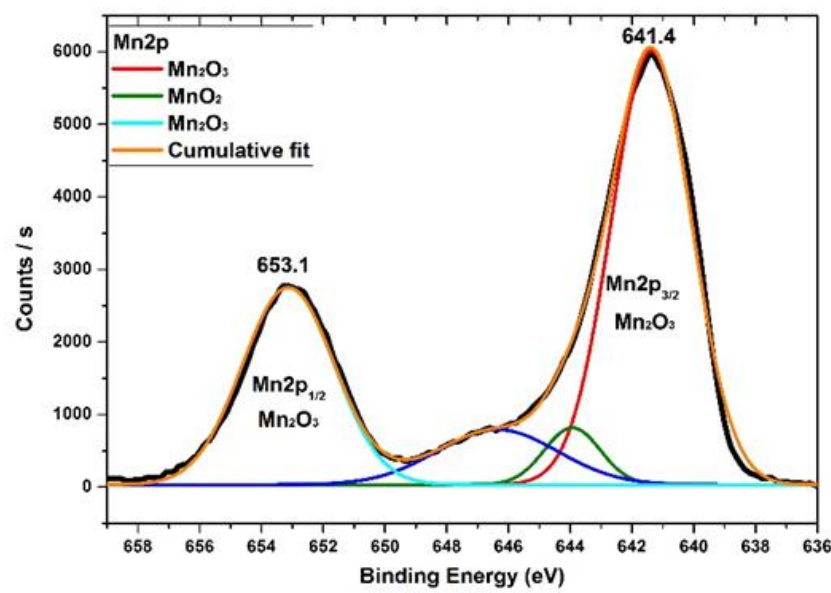

(c)

Figure 1 XPS spectra (a) C1s, (b) O1s, (c) Mn2p obtained after etching the film surface

The oxidation state of manganese can also be estimated based on the difference between the values of the Mn2p3/2 maximum and the Mn-O peak in the O1s spectrum. In the study of various manganese oxides, it was found that with a decrease in the oxidation state, this difference decreases and amounts to $112.2 \mathrm{eV}$ for $\mathrm{MnO}_{2}$, $111.7 \mathrm{eV}$ for $\mathrm{Mn}_{2} \mathrm{O}_{3}$, and $111.1 \mathrm{eV}$ for $\mathrm{MnO}$ [16]. In our case, it is $111.6 \mathrm{eV}$, which indicates the predominant presence of manganese in the $\mathrm{Mn}_{2} \mathrm{O}_{3}$ compound. In the process of ALD with the use of $\mathrm{Mn}(\text { thd })_{3}$ and $\mathrm{O}_{2}$ plasma, there is practically no change in the oxidation state of manganese, and a $\mathrm{Mn}_{2} \mathrm{O}_{3}$ film is formed.

According to the results of an X-ray phase analysis study, no reflections corresponding to manganese oxides were found on the X-ray diffraction patterns. In this regard, it can be concluded that an X-ray amorphous film is possibly formed during the ALD at $275^{\circ} \mathrm{C}$.

\subsection{Electrochemical characteristics}

The electrochemical characteristics of thin films of manganese oxide $\mathrm{Mn}_{2} \mathrm{O}_{3}$ obtained on steel substrates during 1700 ALD cycles are shown in Figure 2. CV (cyclic voltammetry) studies (Figure 2a) showed that during the first scan, as well as in the subsequent 15 , there are intense increases in the current in the anodic region with maxima of $1.3,1.6$, and $2.0 \mathrm{~V}$. Inverse processes are present in the cathodic curve of 0.3 and 0.7 $\mathrm{V}$. The presence of a maximum in the anodic region of $1.6 \mathrm{~V}$ (cathodic curve $0.7 \mathrm{~V}$ ) is associated with the formation of the solid electrolyte interface (SEI film) [5]. In the anodic process, two distinct peaks at $1.3 \mathrm{~V}$ and 2.1 $\mathrm{V}$ could be described to the oxidation of $\mathrm{Mn}^{0}$ to $\mathrm{Mn}^{2+}$ and $\mathrm{Mn}^{2+}$ to $\mathrm{Mn}^{4+}$, respectively [17]. It should be noted that after $15 \mathrm{CV}$ scans intensity of anodic peak at $1.3 \mathrm{~V}$ decreased, and cathodic peaks became more intensive. 
The areas of the anode and cathode parts are comparable in area, which indicates high reversibility of the processes.

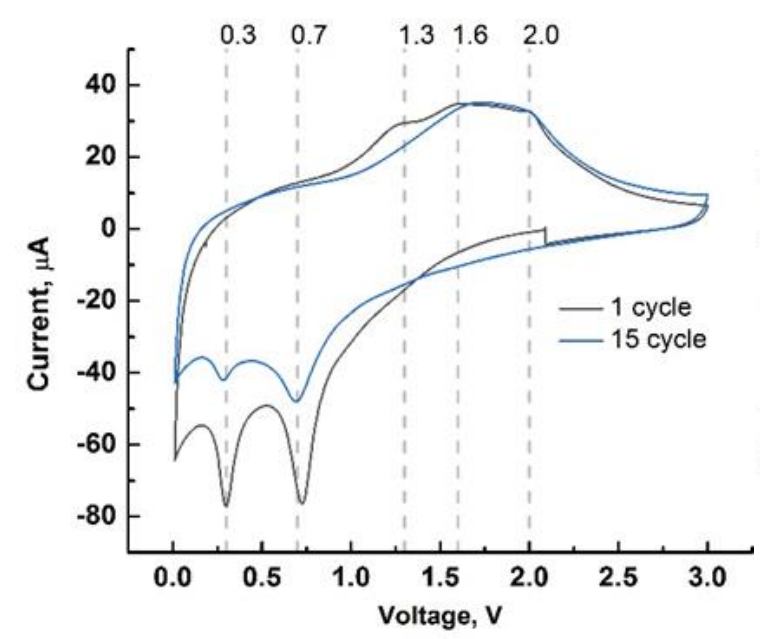

(a)

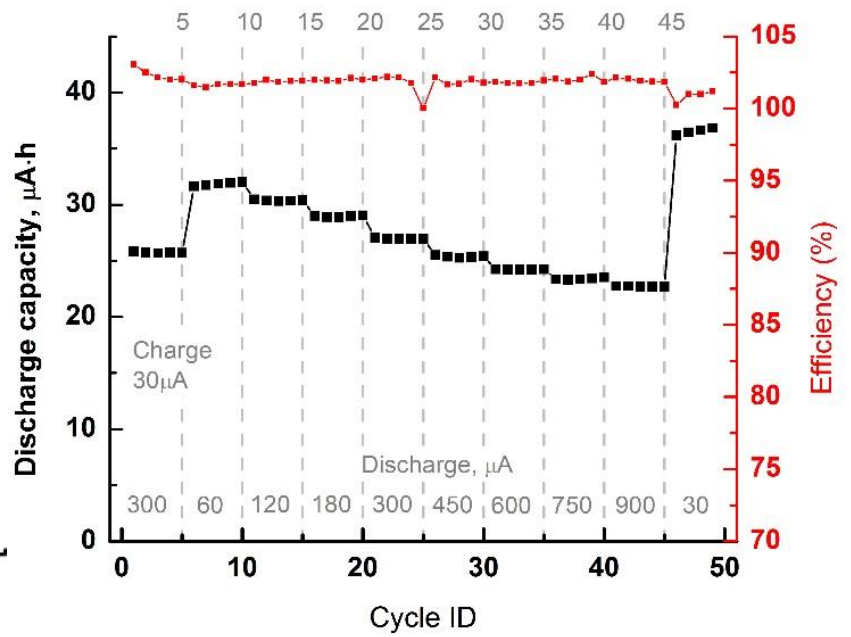

(b)

Figure 2 a - CV curves of manganese oxide coatings, b - electrochemical charge-discharge tests with different currents

Cyclic charge-discharge tests at various current densities were carried out after $15 \mathrm{CV}$ cycles in Fig. 2b. The figure shows the discharge capacity at different current densities from 30 to $900 \mu \mathrm{A}$ (from $0.8 \mathrm{C}$-Rate to $28 \mathrm{C}$ Rate) and coulombic efficiency. An increase in the discharge current density led to the decrease in capacity. The maximum capacity of $37 \mu \mathrm{Ah}$ corresponded to the lower current of $30 \mu \mathrm{A}$ ( $0.8 \mathrm{C}$-Rate), the minimum 24 $\mu \mathrm{Ah}$ for $900 \mu \mathrm{A}$ (28 C-Rate). Thus, the capacitance drop was $35 \%$ of the maximum with 30 times increase in current, which corresponds to the high discharge characteristics of the obtained coatings. The maximum specific volume discharge capacity was $110 \mu \mathrm{Ah} \cdot \mu \mathrm{m}^{-1} \cdot \mathrm{cm}^{-2}$ corresponding to the discharge capacity of $37 \mu \mathrm{Ah}$. For example, NiO prepared by us early has the specific discharge capacity $94 \mu \mathrm{Ah} \cdot \mu \mathrm{m}^{-1} \cdot \mathrm{cm}^{-2}(0.8 \mathrm{C}$-Rate) [5]. Cyclic tests showed the values of the coulombic efficiency are more than $100 \%$, which is associated with the formation of the SEI film and/or associated with adsorption processes occurring on the electrode surface.

\section{CONCLUSION}

ALD growth of Mn-O films was carried out using Bis (2,2,6,6-tetramethyl-3,5-heptanedionato) manganese (III) $\left(\mathrm{Mn}\left(\mathrm{thd}_{3}\right)_{3}\right.$ and remote oxygen plasma as an oxidizing agent. The largest average growth per cycle, 0.12 $\AA /$ cycle, is achieved at a reactor temperature of $270{ }^{\circ} \mathrm{C}$, an evaporator temperature of $190{ }^{\circ} \mathrm{C}$, a pulse time $\mathrm{Mn}$ (thd) $)_{3}-1$ second, and a purge time $\left(\mathrm{N}_{2}\right)-3$ seconds. According to XPS, the film contains predominantly $\mathrm{Mn}_{2} \mathrm{O}_{3}$. The presence of carbon is due to incomplete removal of the residues of the precursor ligands. The crystalline phase of manganese oxides was not found, and the films is amorphous.

According to the results of $\mathrm{CV}$, the films had high electrochemical reversibility. The resulting two peaks at 1.3 $\mathrm{V}$ and $2.1 \mathrm{~V}$ could be described to the oxidation of $\mathrm{Mn}^{0}$ to $\mathrm{Mn}^{2+}$ and $\mathrm{Mn}^{2+}$ to $\mathrm{Mn}^{4+}$. The highest specific discharge capacity is $110 \mu \mathrm{Ah} \cdot \mu \mathrm{m}^{-1} \cdot \mathrm{cm}^{-2}(0.8 \mathrm{C})$. The capacity drop was $35 \%$ of the maximum with an increase in current 30 times, which corresponds to the high discharge characteristics of the obtained coatings.

\section{ACKNOWLEDGEMENTS}

The research was supported by the Ministry of Science and Higher Education of the Russian Federation (State Assignment for basic research 0784-2020-0022). 


\section{REFERENCES}

[1] MALYGIN, A.A., DROZD, V.E., MALKOV, A.A., SMIRNOV, V.M. From V. B. Aleskovskii's "Framework" Hypothesis to the Method of Molecular Layering/Atomic Layer Deposition. Chemical Vapor Deposition. 2015, vol. 21, pp. 216-240.

[2] GEORGE, S.M. Atomic Layer Deposition: An Overview. Chemical Reviews. 2010, vol. 110, pp. 111-131.

[3] MAXIMOV, M., NAZAROV, D., RUMYANTSEV, A., KOSHTYAL, Y., EZHOV, I., MITROFANOV, I., KIM, A., MEDVEDEV, O., POPOVICH, A. Atomic Layer Deposition of Lithium-Nickel-Silicon Oxide Cathode Material for Thin-Film Lithium-Ion Batteries. Energies. 2020, vol. 13, p. 2345.

[4] NAZAROV, D., EZHOV, I., MITROFANOV, I., LYUTAKOV, O., MAXIMOV, M.Y. The Use of TMA as Stabilizing Reagent for the Li-O System Obtained by Atomic Layer Deposition. Key engineering Materials. 2019, vol. 822, pp. 787-794.

[5] KOSHTYAL, Y., NAZAROV, D., EZHOV, I., MITROFANOV, I., KIM, A., RYMYANTSEV, A., LYUTAKOV, O., POPOVICH, A., MAXIMOV, M. Atomic Layer Deposition of NiO to Produce Active Material for Thin-Film LithiumIon Batteries. Coatings. 2019, vol. 9, no. 5, p. 301.

[6] NAZAROV, D.V., MAXIMOV, M.Y., NOVIKOV, P.A., POPOVICH, A.A., SILIN, A.O., SMIRNOV, V.M., BOBRYSHEVA, N.P., OSMOLOVSKAYA, O.M., OSMOLOVSKY, M.G., RUMYANTSEV, A.M. Atomic layer deposition of tin oxide using tetraethyltin to produce high-capacity Li-ion batteries. Journal of Vacuum Science \& Technology A. 2017, vol. 35, pp. 1-11.

[7] MAXIMOV, M.Y., NOVIKOV, P.A., NAZAROV, D.V., RYMYANTSEV, A.M., SILIN, A.O., ZHANG, Y., POPOVICH, A.A. Characterization and Electrochemical Performance at High Discharge Rates of Tin Dioxide Thin Films Synthesized by Atomic Layer Deposition. Journal of Electronic Materials. 2017, vol. 46, pp. 6571-6577.

[8] REDDY, M.V., RAO, G.V.S., CHOWDARI, B.V.R. Metal Oxides and Oxysalts as Anode Materials for Li lon Batteries. Chemical Reviews. 2013, vol. 113, pp. 5364-5457.

[9] JIN, H., HAGEN, D., KARPPINEN, M. Low-temperature atomic layer deposition of crystalline manganese oxide thin films. Dalton Transactions. 2016, vol. 45, pp. 18737-18741.

[10] BURTON, B.B., FABREGUETTE, F.H., GEORGE, S.M. Atomic layer deposition of MnO using Bis(ethylcyclopentadienyl) manganese and H2O. Thin Solid Films. 2009, vol. 517, pp. 5658-5665.

[11] LU, H.L., SCAREL, G., LI, X.L., FANCIULLI, M. Thin MnO and NiO films grown using atomic layer deposition from ethylcyclopentadienyl type of precursors. Journal of Crystal Growth. 2008, vol. 310, pp. 5464-5468.

[12] MATTELAER, F., VEREECKEN, P.M., DENDOOVEN, J., DETAVERNIER, C. Deposition of MnO Anode and $\mathrm{MnO} 2$ Cathode Thin Films by Plasma Enhanced Atomic Layer Deposition Using the Mn(thd)(3) Precursor. Chemistry of Materials. [online]. 2015, vol. 27, pp. 3628-3635, Available from:

https://doi.org/10.1021/acs.chemmater.5b00255.

[13] NIEMINEN, H.E., MIIKKULAINEN, V., SETTIPANI, D., SIMONELLI, L., HONICKE, P., ZECH, C., KAYSER, Y., BECKHOFF, B., HONKANEN, A.P., HEIKKILA, M.J., et al. Intercalation of Lithium lons from Gaseous Precursors into beta-MnO2 Thin Films Deposited by Atomic Layer Deposition. Journal of Physical Chemistry C. 2019, vol. 123, pp. 15802-15814.

[14] MilKKULAINEN, V., RUUD, A., OSTRENG, E., NILSEN, O., LAITINEN, M., SAJAVAARA, T., FJELLVAG, H. Atomic Layer Deposition of Spinel Lithium Manganese Oxide by Film-Body-Controlled Lithium Incorporation for Thin-Film Lithium-Ion Batteries. Journal of Physical Chemistry C. 2014, vol. 118, pp. 1258-1268.

[15] NILSEN, O., FJELLVAG, H., KJEKSHUS, A. Growth of manganese oxide thin films by atomic layer deposition. Thin Solid Films. 2003, vol. 444, pp. 44-51.

[16] MATtElAER, F., BOSSEREZ, T., RONGE, J., MARTENS, J.A., DENDOOVEN, J., DETAVERNIER, C. Manganese oxide films with controlled oxidation state for water splitting devices through a combination of atomic layer deposition and post-deposition annealing. Rsc Advances. 2016, vol. 6, pp. 98337-98343.

[17] CHEN, J.B., WANG, Y.W., HE, X.M., XU, S.M., FANG, M., ZHAO, X., SHANG, Y.M. Electrochemical properties of $\mathrm{MnO} 2$ nanorods as anode materials for lithium ion batteries. Electrochimica Acta. 2014, vol. 142, pp. $152-156$. 